\title{
A 46-year-old man with recurrent embolic events
}

\author{
T. Lorjé1,4 N. Barlo $^{2}$ C. L. A. Reichert ${ }^{1}$ W. de Kanter ${ }^{3}$ - M. A. Sluman ${ }^{1,5}$
}

Published online: 1 September 2017

(c) The Author(s) 2017. This article is an open access publication.

A 46-year-old male with advanced adenocarcinoma of the lung presented with venous thrombosis. Despite anticoagulants, he developed a stroke and bowel ischaemia. Echocardiography revealed mobile structures on the mitral valve and at the pulmonary artery origin (Fig. 1). Although treatment for endocarditis and pulmonary embolism was initiated, his condition deteriorated. However, blood cultures remained negative and fever was absent. Non-bacterial thrombotic endocarditis (NBTE) became more likely after establishing progressive malignancy with PET-CT. NBTE is found in $19 \%$ of patients with malignancy and thrombotic events, but often not recognised [1]. It is distinguished from infective endocarditis by location of the valvular mass, absence of infection, diffuse thickening of valve leaflets and usual absence of valvular dysfunction [2,3]. Treatment involves oncological therapy and anticoagulants [4]. Surgery may be considered in progressive valvular disease or recurrent embolism [5]. NBTE should be part of the differential diagnosis in patients with malignancy and thromboembolic complications.

M. A. Sluman

maayke@sluman.eu

1 Department of Cardiology, Northwest Clinics, Alkmaar, The Netherlands

2 Department of Pulmonology, Northwest Clinics, Alkmaar, The Netherlands

3 Department of Pulmonology, Antoni van Leeuwenhoek Hospital, Amsterdam, The Netherlands

4 Department of Internal Medicine, Alrijne Hospital, Leiderdorp, The Netherlands

5 Department of Cardiology, Jeroen Bosch Hospital, 's Hertogenbosch, The Netherlands
Open Access This article is distributed under the terms of the Creative Commons Attribution 4.0 International License (http:// creativecommons.org/licenses/by/4.0/), which permits unrestricted use, distribution, and reproduction in any medium, provided you give appropriate credit to the original author(s) and the source, provide a link to the Creative Commons license, and indicate if changes were made.

\section{References}

1. Edoute Y, Haim N, Rinkevich D, et al. Cardiac valvular vegetations in cancer patients: a prospective echocardiographic study of 200 patients. Am J Med. 1997;102:252-8.

2. Reisner SA, Brenner B, Haim N, et al. Echocardiography in nonbacterial thrombotic endocarditis: from autopsy to clinical entity. J Am Soc Echocardiogr. 2000;13:876-81.

3. Saric M, Armour AC, Arnaout MS, et al. Guidelines for the use of echocardiography in the evaluation of a cardiac source of embolism. J Am Soc Echocardiogr. 2016;29:1-42.

4. Whitlock RP, Sun JC, Fremes SE, et al. Antithrombotic and thrombolytic therapy for valvular disease: antithrombotic therapy and prevention of thrombosis, 9th ed: American College of Chest Physicians evidence-based clinical practice guidelines. Chest. 2012;141(2 Suppl):e576S-e600S.

5. El-Shami K, Griffiths E, Streiff M. Nonbacterial thrombotic endocarditis in cancer patients: pathogenesis, diagnosis, and treatment. Oncologist. 2007;12:518-23. 

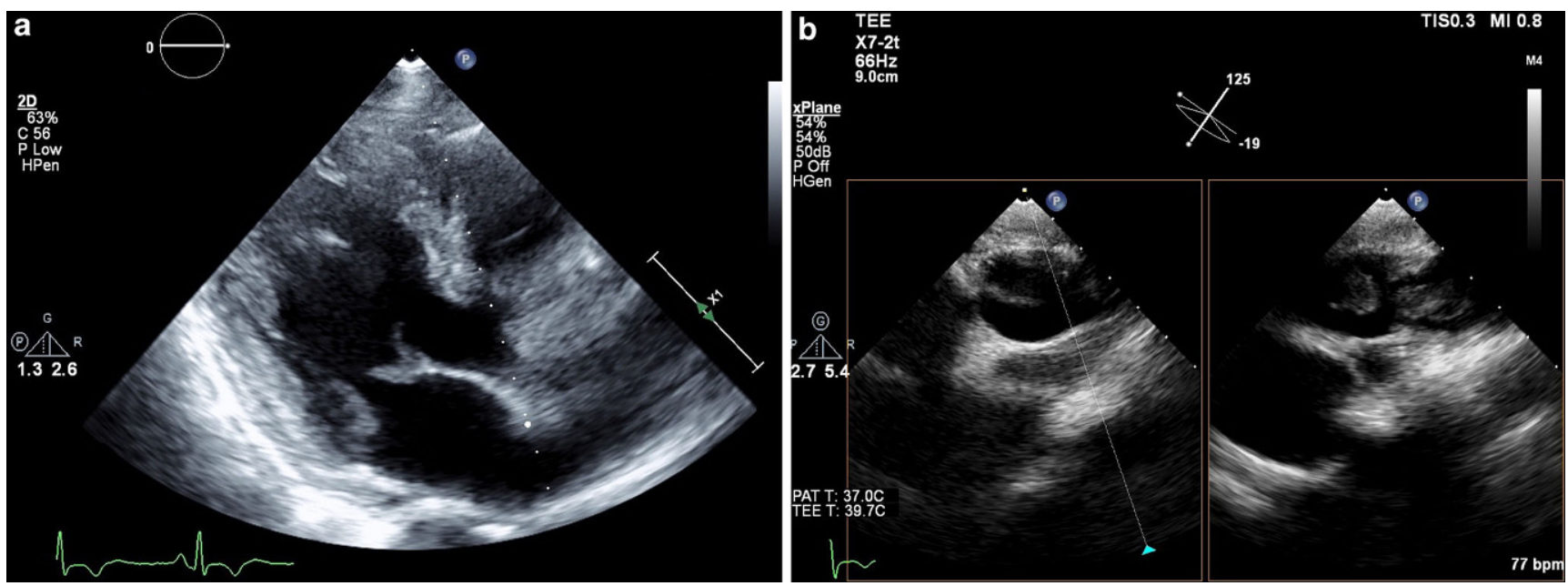

Fig. 1 Transthoracic (a) and transoesophageal echocardiography (b) revealing a mobile structure attached to the ventricular side of the anterior mitral valve leaflet and multiple mobile masses at the origin of the pulmonary artery 